\title{
ENGAJAMENTO E A ÉTICA PRESENTES EM GRUPOS E PÁGINAS SOBRE RADIOLOGIA NA MÍDIA SOCIAL FACEBOOK: UMA ANÁLISE REFLEXIVA
}

\author{
Marcelo Salvador Celestino ${ }^{1}$, Matheus Alvarez ${ }^{2}$, Vânia Cristina Pires Nogueira Valente ${ }^{1}$ \\ Universidade Estadual Paulista - UNESP, Faculdade de Arquitetura, Artes e Comunicação - FAAC, Bauru, SP. \\ Universidade Estadual Paulista - UNESP, Botucatu, SP. E-mail: marcelo.salvador@unesp.br
}

\section{RESUMO}

A mídia social Facebook pode ser vista, na atualidade, como um importante canal de expressão e comunicação em diferentes setores da sociedade. No âmbito da Saúde, o compartilhamento de imagens e pedidos médicos, ou postagens que possam transpassar o limiar da ética profissional, podem acarretar impactos negativos para estudantes e profissionais como um todo. Este trabalho realiza uma análise crítica e reflexiva acerca do engajamento e interações entre os estudantes e profissionais - Técnicos e Tecnólogos em Radiologia -, por meio da seleção e análise retrospectiva de 39 postagens em páginas e grupos no site do Facebook, com o tema Radiologia. A coleta de dados ocorreu no período de setembro a dezembro de 2017. Criou-se um sistema de classificação do teor das postagens em seis tipos diferentes, dentre os quais foram encontrados: satírico $(41,03 \%)$, processos patológicos $(30,77 \%)$, solicitação de exames $(12,82 \%)$, radiografias inusitadas $(7,69 \%)$, literal $(5,13 \%)$ e incitação $(2,56 \%)$.

Palavras-chave: ética; mídia e tecnologia; Radiologia.

\section{THE ENGAGEMENT AND ETHICS PRESENT IN GROUPS AND PAGES ON RADIOLOGY IN SOCIAL MEDIA} FACEBOOK: A REFLECTIVE ANALYSIS

\begin{abstract}
Social media Facebook can be seen today as an important channel for expression and communication in different sectors of society. In Health, the sharing of images and medical requests, or posts that may cross the threshold of professional ethics, can have negative impacts for students and professionals as a whole. This paper conducts a critical and reflective analysis of engagement and interactions between students and practitioners - Radiology Technicians and Technologists - through the selection and retrospective analysis of 39 postings on pages and groups on the Facebook site, under the theme Radiology. Data collection took place from September to December 2017. A classification system of the post content was created in six different types, among which were found: satirical (41.03\%), pathological processes $(30.77 \%)$, request for exams (12.82\%), unusual radiographs (7.69\%), literal (5.13\%) and incitement (2.56\%).
\end{abstract}

Keywords: ethic; media and technology; Radiology.

\section{INTRODUÇÃO}

A sociedade contemporânea está se fundamentando cada vez mais nas relações efetuadas por meio das redes digitais, vistas como um espaço de expressão e influência sociais (CASTELLS, 1999, 2013). As novas relações interativas que ocorrem em mídias sociais têm ganhado destaque graças à convergência dos meios de comunicação, da mobilidade e do desenvolvimento de aparelhos e dispositivos móveis (JENKINS, 2009), como tablets e smartphones, que permitem a qualquer pessoa 
que possua um dispositivo conectado a uma rede e um perfil de usuário em alguma mídia ou rede social, observar, interagir e opinar em diferentes contextos, sobre distintos assuntos e com as mais variadas pessoas.

Neste contexto, surgiu o Facebook, uma plataforma criada em 2004, cujo objetivo inicial era o de servir de suporte para contatos entre jovens acadêmicos, tornando-se, na atualidade, o site (ou plataforma) de redes sociais com maior base de dados no mundo (até o momento de conclusão deste trabalho) (CARLSON, 2010; ROCHA NETO, BARRETO, SOUZA, 2015). Os usuários de mídias e redes sociais em geral são vistos como consumidores e produtores de conteúdo digital, e percebidos como integrantes de um processo digital democrático (LEVINSON, 2009; SCOLARI, 2015; PATEL et al., 2017; WANG, CHOU, BIH, 2017).

Em se tratando do acesso aos sites de redes sociais, ou da internet em geral, o Art.o 2, do Capítulo 1 da Lei n.o 12.965, de 23 de abril de 2014 (BRASIL, 2014), conhecida por Marco Civil da Internet, esclarece que as pessoas possam interagir e se expressar livremente, observando os direitos e preceitos éticos dos cidadãos.

No que tange este trabalho, os chamados Técnicos (TR) e Tecnólogos em Radiologia (TNR), no Brasil, também são conhecidos como profissionais de Técnicas Radiológicas. Estes atuam na área da saúde e industrial (CONTER, 2012, 2016), realizando procedimentos que envolvem radiações ionizantes e não ionizantes. A conduta destes profissionais segue como referência um Código de Ética (CONTER, 2011a) que traz como tônica o respeito aos seres humanos e, sobretudo sua dignidade, tanto profissional, quanto pessoal.

Este artigo realiza uma análise reflexiva a respeito da interação e engajamento dos profissionais da área de Técnicas Radiológicas em postagens por meio do Facebook, seguindo como referência principal o trabalho de Martorell, Nascimento e Garrafa (2016).

A seção interações no Facebook, contextualiza o sistema de interação entre usuários e o conteúdo disponibilizado no site, e uma explanação sobre ética e conduta em mídias sociais.

$\mathrm{Na}$ seção de metodologia da pesquisa, serão esclarecidos os passos para seleção das postagens, a serem descritas nos resultados, na subseção postagens selecionadas. Em discussão, análise e reflexões, serão realizadas correlações entre as postagens, a literatura de fundamentação e o Código de Ética dos referidos profissionais, bem como a análise reflexiva dos autores, finalizando $\mathrm{o}$ artigo com as considerações finais.

\section{Interações no Facebook}

De acordo com Wang, Chou e Bih (2017), as interações realizadas por meio do Facebook alcançam projeções de cerca de 45 bilhões de likes (curtidas) diários, upload de mais de 300 milhões de fotos e mais de 1 milhão de links compartilhados em um período de 20 minutos.

As interações podem ocorrer por meio de diálogos de texto e interações por intermédio de botões de ações, que expressam sentimentos e estados de espírito entre usuários conectados ou não ao seu perfil, ou por via de postagens em grupos e páginas diversas, com pessoas que nem sempre fazem parte da sua rede virtual de contatos. O significado da imagem de cada botão de interação no Facebook é carregado por interpretações genéricas e subjetivas. Para Souza (2016), os textos e as reações de cada botão podem significar:

- Curtir: a mensagem foi lida ou vista; o usuário achou legal ou concorda com a mensagem;

- Amei: o usuário gostou muito da mensagem;

- "Haha": entende-se como algo engraçado, mas dependendo do contexto, pode ser entendido como sarcasmo;

- Uau: significa que a postagem causou espanto, que o usuário ficou impressionado, surpreso ou desacreditado do conteúdo;

- Triste: a postagem pode ter causado sensação de tristeza, comoção;

- "Grr": o usuário discorda da postagem, não gosta ou sentiu raiva em relação ao conteúdo.

Cada um desses botões isolados pode ser comparado a um meio que expressa uma determinada mensagem (McLUHAN, 1964). A respeito do que ocorre em um vídeo qualquer, mesmo sem falas, por exemplo, em que a mensagem é imagética, os botões de interação transmitem uma mensagem por si só, ainda que sejam passíveis de interpretações subjetivas. Vêse, na figura 1 , da esquerda para a direita, os botões Curtir, Amei, "Haha", Uau, Triste e "Grr". 
Figura 1. Botões de interação do Facebook

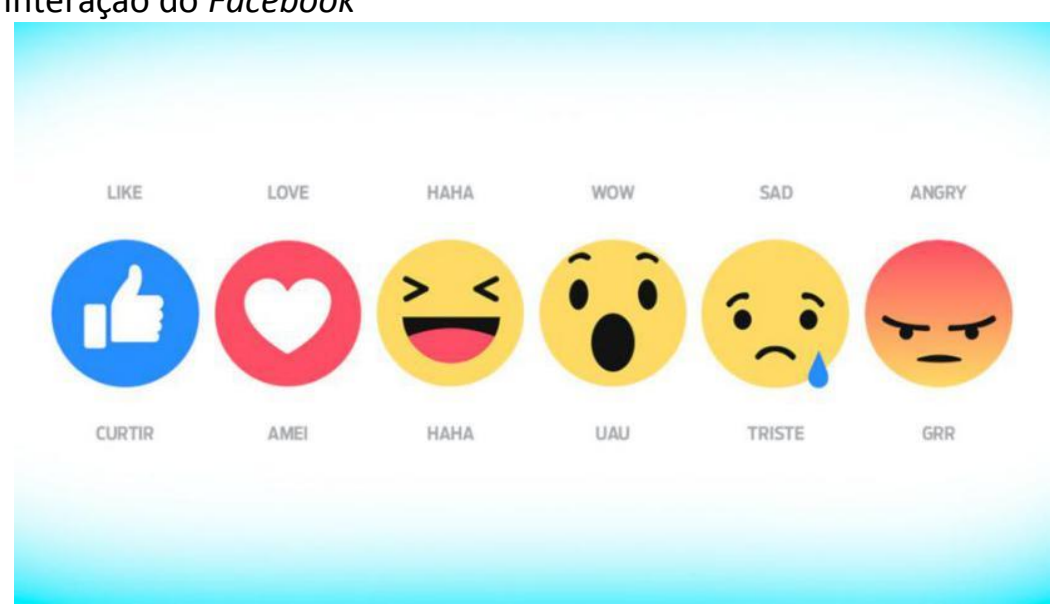

Fonte: Moreira (2016)

Para Barbosa (2011), em um contexto institucional, a criação de um código de ética e conduta acerca de mídias sociais para seus funcionários objetiva a preservação da imagem institucional, que pode ser atrelada ao perfil de usuários em mídias sociais, orientando sobre aspectos que tangem a propriedade intelectual e o compartilhamento de informações financeiras da própria empresa. Ainda de acordo com o Barbosa (2011, p. 6):

Para as organizações, criar um documento com essas orientações é fundamental, pois o meio virtual pode propiciar ao indivíduo a sensação ou permitir o anonimato. Dessa forma, muitos pensam que emitir uma opinião sobre um produto da empresa, sem se identificar como funcionário da organização, realizar uma ação de marketing 'duvidosa' ou divulgar informações sigilosas podem não acarretar em problemas ou danos. Trata-se de um enorme equívoco. Uma atitude única, um ato sem pensar pode prejudicar todo um trabalho de relacionamento.

A respeito da ética e disciplina em ambientes digitais, a Secretaria de Comunicação Social (SECOM, 2014, p. 107) entende que:

O limite entre o pessoal e o profissional está cada vez mais tênue. $E$ justamente por esta razão é preciso ter cuidado redobrado, porque a partir do momento em que uma pessoa torna pública uma opinião e expressão, ela também assume os riscos, responsabilidades e consequências sobre estas informações, e isso vale também para o universo digital.

Em perspectiva semelhante à da SECOM (2014), Recuero (2011) considera que a as pessoas em si são a própria rede social, e as plataformas, como por exemplo, o Facebook, são vistas como sites de redes sociais. Para Recuero (2011, p. 3),

Embora os sites de redes
sociais atuem como
suporte para as interações
que constituirão as redes
sociais, eles não são, por si,
redes sociais. Eles podem
apresentá-las, auxiliar a
percebê-las, mas é
importante salientar que
são, em si, apenas
sistemas. São os atores
sociais, que utilizam essas
redes, que constituem
essas redes.

Assim, é o grupo de usuários reunidos por interesses mútuos, sejam eles pessoais, profissionais, educacionais, entre outros, que formam uma rede social, inserida em um site, plataforma ou sistema. 


\section{METODOLOGIA DA PESQUISA}

O presente artigo é de caráter analítico reflexivo. Para contextualizar o cenário dos fatos, foi realizada uma pesquisa por meio da barra de busca do Facebook com o descritor Radiologia, no mês de setembro de 2017, e a coleta de dados (das postagens) ocorreu no período de setembro a dezembro do referido ano.

$O$ universo de estudo se relaciona com os estudantes da área de Educação Profissional e Tecnológica em Radiologia, e com os referidos profissionais, de modo que não foram visitados grupos ou páginas específicas para médicos radiologistas, por não integrarem o recorte do objeto de estudo. Na busca, foram encontrados 99 grupos, sendo que o menor deles continha 26 membros e o maior aproximadamente 26.000 membros. Também foram encontradas 102 páginas, das quais a menos popular continha aproximadamente 228 curtidas e a mais popular aproximadamente 127.000 curtidas.

Foram visitados 15 grupos e 15 páginas de forma aleatória, bem como 15 perfis (abertos ao público) de pessoas que interagiram nesses ambientes digitais, sendo selecionadas 39 postagens que contivessem aderência e justificassem a exposição do tema. Destas 39 postagens, foram descritas detalhadamente um exemplo de cada item de referência (Tabela 1) de A - F, criado para classificar o teor das mensagens, de acordo com uma percepção geral em seis tipos diferentes de postagens.

Tabela 1. Classificação dos tipos de mensagem

\begin{tabular}{cclcc}
\hline REFERÊNCIA & TIPO & \multicolumn{1}{c}{ TEOR } & QUANTIDADE \\
\hline A & Satírico & $\begin{array}{l}\text { Figuras ou imagens com teor irônico ou } \\
\text { engraçado, como por exemplo, os memes. }\end{array}$ & 16 \\
\hline B & $\begin{array}{c}\text { Solicitação de } \\
\text { exames }\end{array}$ & $\begin{array}{l}\text { Solicitações de exames médicos fora do } \\
\text { padrão técnico. }\end{array}$ & 5 \\
\hline C & $\begin{array}{c}\text { Radiografias } \\
\text { inusitadas }\end{array}$ & $\begin{array}{l}\text { Exposições deliberadas, reais ou } \\
\text { montagens. }\end{array}$ & 3 \\
\hline D & $\begin{array}{c}\text { Processos } \\
\text { patológicos }\end{array}$ & $\begin{array}{l}\text { Imagens diagnósticas evidenciando } \\
\text { doenças, e sendo interpretadas. }\end{array}$ & 12 \\
\hline E & Literal & $\begin{array}{l}\text { Situações fora do contexto técnico, } \\
\text { representando sátira. }\end{array}$ & 2 \\
\hline F & Incitação & Mensagens com influência negativa. & 1 \\
\hline
\end{tabular}

Fonte: Os autores (2017).

Foi identificado um tipo de postagem em que apareciam os dados do paciente em um exame de imagem, mas a abordagem deste item foi descartada do recorte deste trabalho por necessitar de uma abordagem mais específica. Por tal razão, este item não será descrito, mas o tema será comentado nas discussões, dado a sua relevância. Não foram selecionadas postagens dos perfis de usuários, pois não foram encontradas postagens visíveis sobre o tema proposto.

\section{RESULTADOS}

A Figura 2 apresenta a classificação das postagens, de acordo com o teor de classificação das mensagens. 
Figura 2. Quantidade e teor das postagens

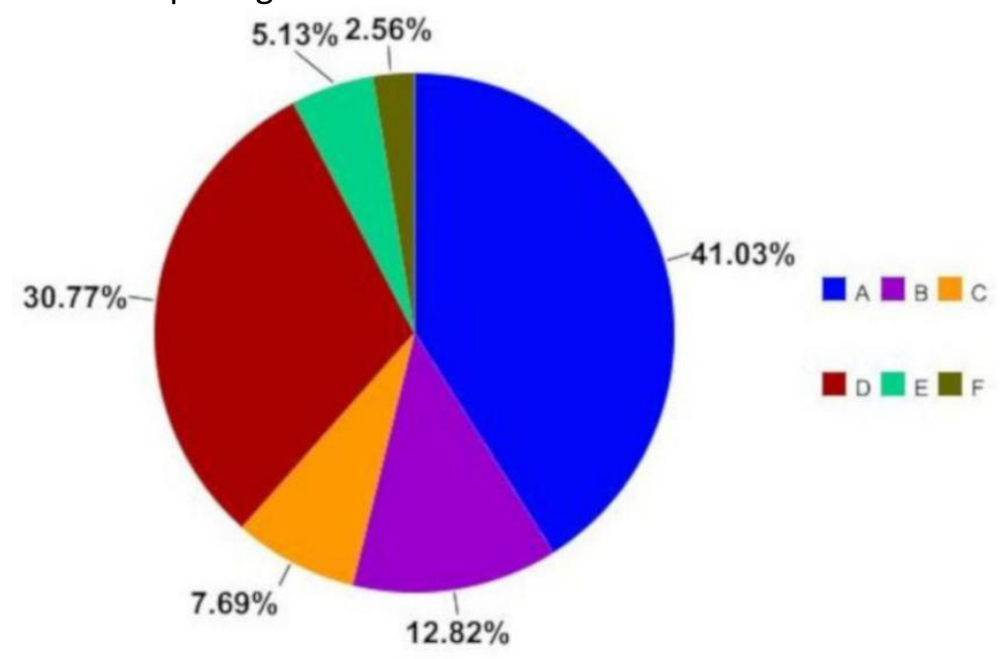

Fonte: Os autores (2017).

Legenda: $\mathrm{O}$ teor das mensagens está de acordo com as letras: A) satírico; B) solicitação de exames; C) radiografias inusitadas; D) processos patológicos; E) literal; F) incitação.

As postagens selecionadas foram arquivadas por meio da captura de tela pelo programa Lightshot, e salvas em formato PDF. Em seguida, passaram por um processo de observação simples, leitura e interpretação subjetiva e espontânea do conteúdo (GIL, 2008). Ressalta-se que não houve participação, interação ou influência dos autores sobre as postagens e sobre o público observado.

Para manter a privacidade dos autores das postagens, as imagens e os dados dos autores de comentários, e publicações, todos extraídos do Facebook, não serão referenciados, sendo substituídos por $* * * *$ (asteriscos) - uso comum acadêmico para omitir identidade, quando necessário.

\section{Postagens selecionadas}

A primeira postagem (Figura 3) refere-se à imagem de Wilhelm Conrad Roentgen, descobridor dos raios $X$, com o a frase "Deus tá vendo... Você escondendo as películas de exames que você repetiu!!!" ${ }^{1}$. No total foram computadas 878 interações entre curti, amei e "Haha".

\footnotetext{
${ }^{1}$ A ortografia foi conservada, levando-se em consideração o registro linguístico original presente no comentário.
} 
Figura 3. Postagem 1

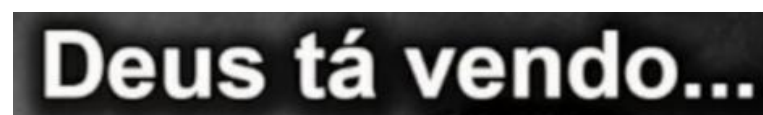

Fonte: Os autores (2017).

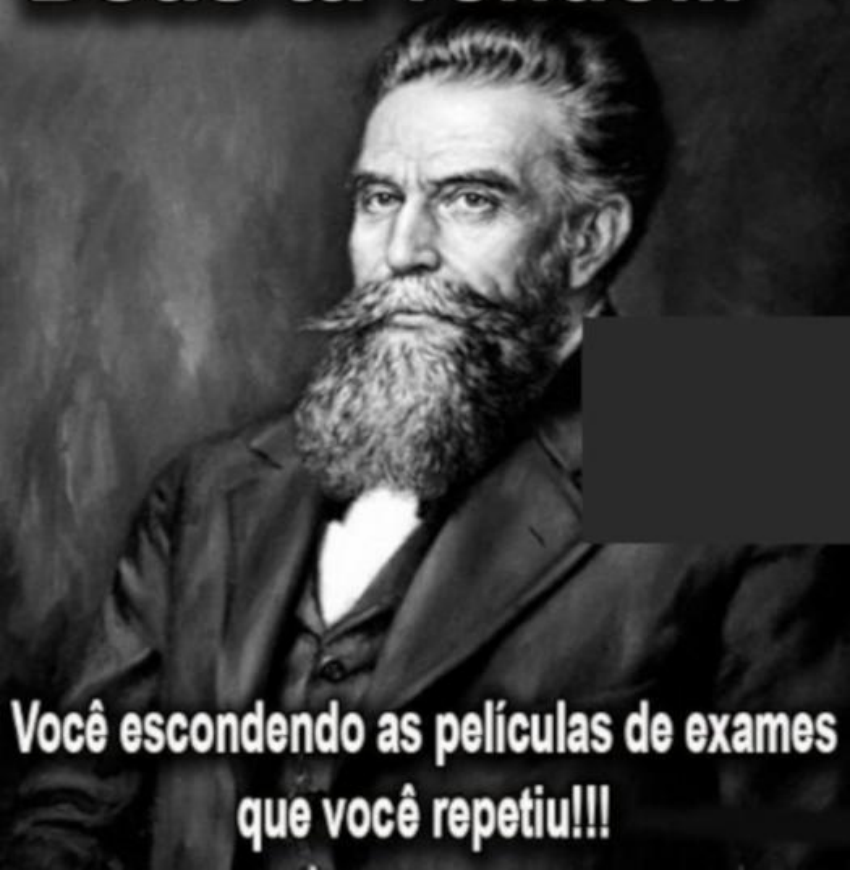

A segunda postagem refere-se a uma possível solicitação médica que, no entendimento de quem postou, estava errada. Na solicitação estava descrito como motivo da solicitação TEP (sigla para tromboembolismo pulmonar), sugerindo a suspeita médica para a hipótese diagnóstica, enquanto a escrita do exame ou procedimento solicitado, estava especificado como "TC de crânio como protocolo para TEP". Houve 26 interações do tipo curtir, uau e triste, 24 comentários e 4 compartilhamentos.
A terceira postagem (Figura 4) selecionada é a imagem de perfil de uma determinada página, e demonstra uma imagem radiográfica de uma pessoa com fone de ouvido e microfone, na qual supostamente foram expostos (à radiação, para formação da imagem) crânio e face, parte de uma mão e coluna cervical. A princípio, acredita-se ser uma radiografia, mas não se sabe se também poderia ser uma montagem. Nesta postagem não houve interações.

Figura 4. Postagem 3

Fonte: Os autores (2017).

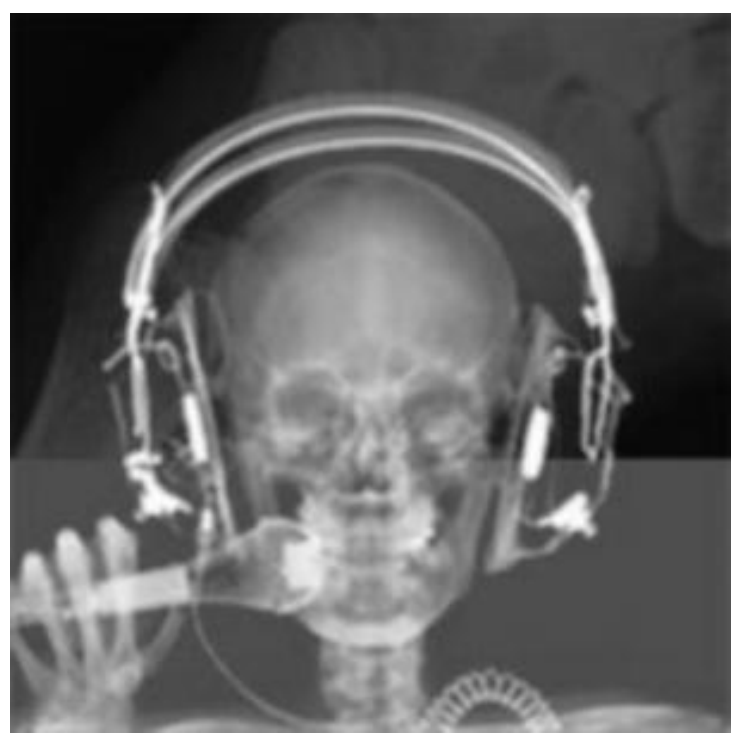


$\mathrm{Na}$ quarta postagem (Figura 5), vê-se uma radiografia em perfil de crânio, com uma alteração morfológica, sugestiva de um processo patológico (círculo vermelho). A legenda da postagem estava descrita como "Comentem o tipo de patologia encontrada no exame". Houve 3 curtidas, 3 comentários e 1 compartilhamento.

Figura 5. Postagem 4

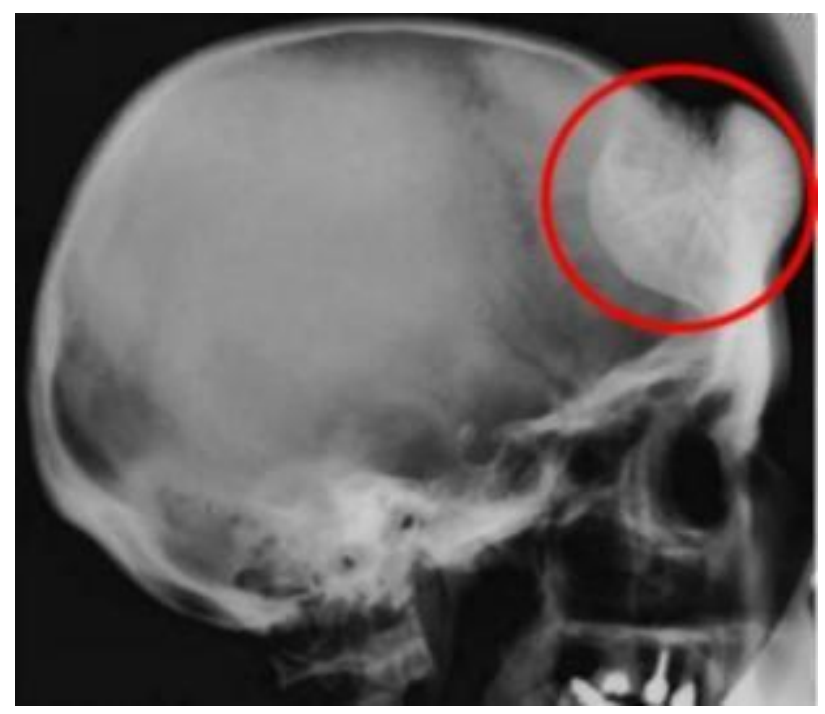

Fonte: Os autores (2017).

A postagem 5 (Figura 6) refere-se a uma atitude de alguém que levou ao pé da letra a solicitação médica de "RX da cadeira". Na figura 7 , vê-se uma cadeira posicionada sobre a mesa de exames, com o tubo de raios $X$ posicionado, com a luz de colimação acesa, simulando um posicionamento radiográfico. No texto da postagem 5 constava a descrição: "Raio $X$ da cadeira? Beleza ... Assim está bom??? Kkkkkk AP (anteroposterior) e axial de cadeira..." ${ }^{2}$. Houve mais de 1.200 interações entre haha, curtir e amei, e 226 compartilhamentos.

\footnotetext{
${ }^{2}$ A ortografia foi conservada, levando em consideração o uso linguístico original da postagem.
} 
Figura 6. Postagem 5

Fonte: Os autores (2017).

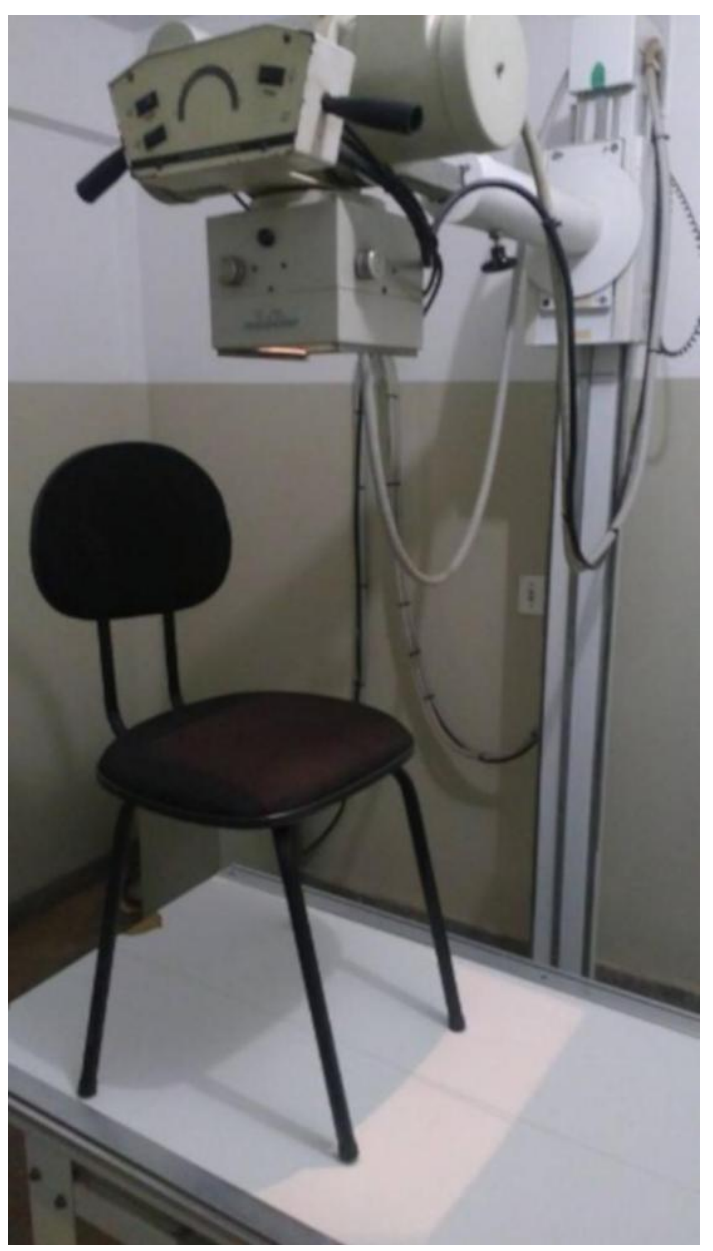

A postagem 6 reforça a ideia de rir e debochar de solicitações médicas, com a seguinte legenda: "Se você tiver pedido de exames estranhos, postem inbox, endereçados para o $* * * *^{3}$. Depois de me certificar de deixar os nomes dos pacientes bem encobertos e dos locais também, eu posto. Vamos rir um pouco...". Houve 9 curtidas.

\section{DISCUSSÃO, ANÁLISE E REFLEXÕES}

$A$ rede social Facebook tornou-se um dos maiores canais de comunicação e expressão da atualidade, trazendo novas formas de interação entre as pessoas, dentre as quais estão: a exposição de opiniões e ideias. Porém, no decorrer da pesquisa foi possível perceber que os grupos e páginas analisados, por diversas vezes acabaram desperdiçando o potencial desta rede social enquanto canal de aprendizagem, para dar lugar a debates que destoam da formação profissional dos envolvidos, e que podem transpassar os limites da ética profissional.
Os números descritos por Wang et al. (2017) refletem uma cultura de relacionamentos cada vez mais voltada para o uso de plataformas digitais. Embora exista uma sensação de liberdade e impessoalidade provocada pela diferença de espaço, existente entre os usuários do Facebook, onde cada pessoa tem liberdade para expressar suas opiniões e pontos de vista, cada cidadão é responsável pelo que escreve e compartilha, principalmente quando o usuário possa estar vinculado a um ambiente ou categoria profissional.

Os diversos tipos de engajamento e relações entre as pessoas e as mensagens são importantes nas novas relações com a informação, e no impacto estrutural da sociedade (MCLUHAN, 1964). Isso é perceptível de forma acentuada em uma perspectiva contemporânea, em que os usuários de mídias digitais passaram a ter maior amplitude de voz e a vivenciar uma sensação de empoderamento, a partir do momento em que podem interagir e expressar suas ideias abertamente (BRASIL, 2014).

\footnotetext{
${ }^{3}$ Nesta parte omitida por meio dos asteriscos, constava o contato para envio de imagens referentes ao tema.
} 
As postagens analisadas evidenciaram que o debate de ideias tem cedido lugar a críticas, sátiras e postagens debochadas a respeito do trabalho de outros profissionais. Isso fica evidente ao analisarmos o gráfico em que, a maior parte das postagens $(41,03 \%)$, foi do teor satírico, em que situações que poderiam ser consideradas importantes oportunidades para a discussão da forma correta de se agir frente a um erro, como por exemplo a da Postagem 1, acabaram sendo vistas como algo engraçado.

Sobre a Postagem 1, o momento do estágio curricular obrigatório é importante para o contato dos estudantes com o seu futuro ambiente e realidade profissional e, além disso, é um momento de prática por meio da repetição, observação e orientação para a realização de exames (OLIVEIRA, 2006; CONTER, 2011b). Por se tratar de películas radiográficas, sabe-se que a postagem se refere à chamada Radiologia Convencional, na qual os exames passam por um processo de revelação química para formação da imagem final. Repetir exames significa reexpor o paciente a outra dose de radiação ionizante, gastar novo material, atrapalhar o fluxo de atendimento no serviço, dentre outras situações que prejudicam o bom andamento do setor. Além disso, ocultar uma película significa que não houve uma quantificação rigorosa da perda de materiais do setor, e isso impactaria nos indicadores utilizados pelo gestor para analisar o material utilizado, podendo influenciar inclusive no setor de compras da instituição. Percebe-se que a intenção de tal postagem foi satirizar uma situação que foi subjetivamente correlacionada à prática de estágio. Não houve interações do tipo "Grr", o que pode significar que ninguém discordou da postagem ou desaprovou, o fato de se esconder uma película quando um exame é repetido.

Ainda sobre a Postagem 1, a questão em foco não é o erro de exame, mas sim o teor satírico da postagem. Uma vez que um exame foi repetido e seu erro "ocultado" de seu preceptor ou responsável pelo estágio, subentende-se que o estagiário perdeu a oportunidade de ter um erro corrigido, e assumiu uma postura pouco ética e profissional ao deixar de admitir um erro, o que vai contra o parágrafo 4o do Art. 18 do Código de Ética (CONTER, 2011a) que, sobre as responsabilidades profissionais, orienta que os profissionais de Técnicas Radiológicas assumam as responsabilidades de seus atos. Este tipo de postagem pode também refletir uma realidade que precisa ver observada, a partir do momento em que parece uma prática normal e capaz de influenciar a opinião de estudantes.

Sobre a Postagem 2, o protocolo para TEP na solicitação médica é utilizado, de modo geral, para pesquisa de trombos em vasos na região do mediastino. Cada serviço de imagem detém seu próprio protocolo de exames, que varia de acordo com fatores diversos, como por exemplo, o tipo de equipamento utilizado e a equipe de médicos radiologistas, responsáveis pelos laudos.

A Tomografia Computadorizada (TC) é um método de Diagnóstico por Imagem que utiliza radiação ionizante e permite o estudo de estruturas anatômicas e processos patológicos por meio de cortes seccionais, que podem ser reformatados em diferentes vistas ou perspectivas, cujas imagens são apresentadas de forma digital em uma tela de computador (ROMANS, 2011). De maneira convencional, os exames de TC são realizados por partes individuais do corpo: Neurologia (cabeça, pescoço e colunas), Medicina Interna (tórax e abdome) e Músculo Esquelético (membros superiores e inferiores e suas articulações), além dos estudos de Angiotomografias (Angio-TC), para pesquisa de alterações e patologias vasculares. Em caso de dúvidas quanto a uma solicitação, cabe ao profissional que irá realizar o exame procurar o médico solicitante para esclarecer qual a sua necessidade para avaliação diagnóstica da imagem, aplicando o protocolo correto. A solicitação de exames compete, neste caso, apenas ao médico, mas caberia ao TNR, quando necessário, sugerir protocolos, bem como a melhor aplicação das técnicas radiológicas (CONTER, 2012).

$\mathrm{Na}$ Postagem 2 houve um total 26 interações. As interações de uau e triste levam ao entendimento de que tais usuários são convictos de que o médico tenha cometido um erro. Comentários como "e olha que não é médico cubano" e "[...] tem como piorar, será?" representam um julgamento do médico solicitante, e uma crítica generalista aos médicos cubanos. Isso pode ferir o princípio constitucional da igualdade, descrito na Constituição Federal (CF), Título II, Capítulo I, Art. 5o (BRASIL, 1988) que diz que aborda a igualdade do ser humano perante a lei.

Percebem-se, ainda, opiniões com uma tendência a desqualificar outro profissional, como visto nos comentários "o que me dizem 
desse pedido médico?", "essa doeu" e "reza para não pegar um médico desses". Isso favorece a criação de um ambiente narcisista intelectual, que remete ao narcisismo descrito por McLuhan (1964), em que se cria um ambiente de disputa sobre quem tem maior conhecimento técnicocientífico, algumas vezes hostil, por parte dos engajados, e que destoa dos preceitos éticoprofissionais previstos no Código de Ética destes profissionais (CONTER, 2011a).

$\mathrm{Na}$ postagem 3, apesar de não estar claro se é de fato uma radiografia, ou montagem, serve como exemplo que leva ao entendimento do descumprimento dos princípios de proteção radiológica. De acordo com o princípio da justificativa, as exposições aos raios $X$ só devem ser realizadas mediante solicitação de médico ou dentista, de modo que não existe limite de dose para esses casos, e não deve haver exposição deliberada dos raios X (ANVISA, 1998). Na época do descobrimento dos raios $X$, existia uma cultura deliberada da exposição aos raios $X$, a ponto de as pessoas reunirem-se em praça pública para realizar radiografias diversas sem necessidade. Com a percepção e descoberta dos efeitos biológicos oriundos das exposições às radiações ionizantes, originaram-se estudos de dosimetria e proteção radiológica, que culminaram em uma série de legislações que visam a proteção das esquipes, do público geral e do paciente (MOORE, 2017).

O compartilhamento em mídias sociais de imagens desse tipo, pode estimular os estudantes em processo de formação a realizarem o mesmo feito, pois por uma questão de insipiência, podem considerar isso como algo normal. A análise também permite questionar a qualidade da formação e o grau de conhecimento sobre os preceitos de proteção radiológica (e éticos) por parte de quem realizou a radiografia, o conhecimento sobre o regimento da instituição em que se trabalha, do ponto de vista da conduta, e o comportamento profissional em momentos de ociosidade. Outro ponto é que os estudantes que acompanham e interagem com esse tipo de postagem, podem considerar realizar exposições radiográficas deliberadas e fora do contexto adequado, julgado uma prática comum, o que pode levar a uma série de exposições desnecessárias, colocando a si próprio e a outras pessoas ao risco das radiações ionizantes, simplesmente pelo fato de compartilhar uma imagem inusitada em mídias sociais.
No que tange as patologias por imagem, é importante que os estudantes e profissionais que realizam os exames conheçam os processos patológicos e indicações de exame, para otimizar a dinâmica de aplicação dos protocolos e das técnicas radiológicas, promovendo, assim, uma imagem com qualidade suficiente para colaborar com o diagnóstico mais preciso possível por parte do médico radiologista. $O$ tipo de postagem que envolvia processos patológicos, resultou em $30,77 \%$, o que significa que este também é um assunto de grande interesse dos engajados nesta rede.

Os comentários da Postagem 4, "Osteoblastoma" e "osteoma", são denominações de patologias (doenças), e a interpretação de imagens com finalidade de laudo, é prerrogativa e atribuição privativa médica (BRASIL, 2013). Por isso, opiniões sugestivas para caracterização de patologias por imagem, por parte dos estagiários ou profissionais que realizam exames, devem ser cuidadosas, para que não haja o transpasse da linha tênue que separa as atribuições profissionais, e não sejam mal interpretadas, de modo que o profissional de Técnicas Radiológicas observe sempre os limites da sua atuação profissional (CONTER, 2011a).

A palavra cadeira é um termo popular/coloquial para designar os ossos do quadril. Logo, "RX de cadeira D" pode ser entendido com o estudo radiográficos dos ossos do quadril direito. Na Postagem 5, o usuário que publicou a fotografia, entendido como profissional, em uma atitude provocativa e debochada, colocou uma cadeira sobre a mesa de exames e simulou a realização de um exame. Ainda que a solicitação médica tenha sido feita fora das normas técnicas, como especificado em Whitley et al. (2005, p. 148) "Antero-posterior pélvis" (em Português Pelve em AP), tal atitude reflete a falta de respeito com a sala e equipamento de exames, sabendo que a mesa será utilizada para que outros pacientes sejam radiografados. Também remete ao desperdício de tempo que, uma vez ocioso, poderia ser gasto para realizar outras atividades no setor. Outro ponto é que, a exemplo das postagens anteriores, tal atitude pode servir de exemplo negativo para estudantes.

Outro fator preocupante é a percepção evidenciada sobre a falta de conhecimento de mundo e de contextos e nuances culturais que possam vir a cercar o profissional, que não 
compreende, ou não quer compreender, a colocação popular da palavra cadeira como a região dos ossos do quadril. Tal percepção, pode ser vista como parte das competências necessárias para atuação de um profissional dentro de uma perspectiva de globalização (BLOCH; WHITELEY, 2011).

A mesa de exames é o local em que os pacientes serão posicionados para a realização dos mesmos, por isso deve estar sempre limpa e higienizada, para o atendimento cuidadoso a cada exame. Sobre o engajamento com a postagem, até a data havia mais de 1.200 reações entre gostei, amei e "haha", além de 226 compartilhamentos. Dentre os comentários, não houve contestação ou comentários de reprova para esta atitude, o que nos leva a entender que as pessoas não estão se atentando para a seriedade do trabalho ou à imagem negativa que isso possa trazer para os profissionais, ou ainda que preferem preservar sua imagem à expressar opinião contrária à da maioria.

A Postagem 6 incita e pede que os usuários enviem "pedidos de exames estranhos", para que eles possam "rir um pouco". Neste ponto, olhando pela óptica inversa, indaga-se: qual Profissional das Técnicas Radiológicas gostaria de ter seus erros e falhas expostos, para que fossem motivo de riso e piada em qualquer ambiente, sobretudo em mídias sociais?

A exposição dos dados do paciente/cliente é um cuidado que precisa ser observado no compartilhamento de imagens em mídias sociais. Vale ressaltar que, embora a postagem em que os dados do paciente aparecem tenha sido deletada, e esse tipo de postagem não tenha resultado em amostra para a presente pesquisa, o resultado pode ser diferente ao ampliar o espectro de pesquisa e coleta de uma amostra maior.

De acordo com Art. 6o do referido Código de Ética (CONTER, 2011a): "ao Tecnólogo, Técnico e Auxiliar em Radiologia é expressamente vedado fornecer ao cliente/paciente, informações diagnósticas verbais ou escritas sobre procedimentos realizados". Ainda de acordo com o referido Código de Ética (CONTER, 2011a), o Art. 24o constitui como infração ética no parágrafo I "revelar, sem justa causa, fato sigiloso de que tenha conhecimento em razão do exercício da profissão", e no parágrafo III "fazer referência a casos clínicos identificáveis". As imagens do tipo selfie em ambientes hospitalares, têm sido vistas como polêmicas, como por exemplo, as enfermeiras que postaram fotos ao lado de uma paciente debilitada (HORA 7, 2016), e o compartilhamento de dados sigilos sobre o estado de saúde de pacientes tem ocasionado demissão de funcionários (HERDY, 2017).

O Código de Ética dos Profissionais das Técnicas Radiológicas não aborda diretamente aspectos referentes à atuação e comportamento em redes ou mídias sociais. Também não foi encontrado material específico sobre o tema para estes profissionais, ficando ao encargo do bom senso geral dos usuários, estudantes e profissionais de Técnicas Radiológicas, manterem uma postura e comportamento éticos no Facebook, ou ambientes digitais e/ou redes sociais em geral.

De certa forma, os grupos e páginas pesquisadas deixam de explorar o potencial do Facebook como um canal para discussão de ideias, temas transversais e educativos, para ceder a postagens que podem contribuir para que seja criada uma imagem negativa da categoria, ao parecer que é uma prática comum brincar de radiografar objetos, ou rir e debochar de outros profissionais, demonstrando a falta de interiorização dos preceitos éticos, e respeito ao ser humano como um todo.

Neste contexto, Martorel, Nascimento e Garrafa (2016, p. 21) consideraram a necessidade da fiscalização de ambientes virtuais e da conduta profissional pelos órgãos responsáveis:

Os Conselhos de classe
que fiscalizam as
diferentes profissões de
saúde devem estar
atentos para a conduta
virtual de seus inscritos,
desenvolvendo atividades
permanentes tanto de
orientação quanto de
averiguação de possíveis
transgressões éticas.
Considerando que o uso
das mídias sociais é
recente, também seria
importante que os cursos
profissionais da área da
saúde incorporassem, nas
universidades e demais
instituições de Ensino
Superior, discussões
relativas à publicação de
imagens de pacientes na
internet, papel a ser
encabeçado pelas


disciplinas de Bioética, priorizando discussões interdisciplinares

transversais durante todo o período de formação dos estudantes (MARTOREL, NASCIMENTO, GARRAFA, 2016, p. 21).

Sobre isso, no site do Instituto de Medicina Integral Professor Fernando Figueira (IMIP), a seção Notícias (NOTíCIAS, 2018), comenta o posicionamento do Conselho Federal de Medicina (CFM) e do Conselho Federal de Enfermagem (Cofen), que proíbem, por meio de resoluções, o compartilhamento de fotos do tipo selfie ou de pacientes em redes sociais.

Assim, entende-se que para que haja disciplina e ganho de credibilidade dos profissionais e estudantes da área operacional da Radiologia em ambientes digitais, seja preciso a conscientização e a abordagem do tema por intermédio de um esforço conjunto entre órgãos reguladores, como CONTER e CRTRs (Conselhos Regionais dos Tecnólogos, Técnicos e Auxiliares em Radiologia), instituições de ensino e educação profissional e tecnológica em Radiologia, e dos profissionais que atuam na área. Também, espera-se que haja uma reflexão individualizada de cada um, sobre o teor do conteúdo postado e dos comentários e opiniões expressados durante a interação com as postagens e/ou outras pessoas envolvidas nas publicações.

\section{CONSIDERAÇÕES FINAIS}

Este trabalho analisou postagens de páginas e grupos de TR e TNR em Radiologia da mídia social Facebook, a fim de compreender a maneira como profissionais e estudantes correlacionam o código de ética da categoria profissional com a apropriação de um espaço digital para a expressão de opiniões por meio de interações e comentários.

Pode-se perceber que as páginas e grupos, em diversos momentos, tem seu potencial enquanto canal de discussão construtiva (e aprendizagem) subjugado frente à postagens e expressão de ideias que podem ser interpretadas de maneira negativa, e pouco ética, impactando a categoria profissional como um todo. Também foi possível perceber o uso da sala e equipamento de raios $X$ para a aquisição de imagens sem qualquer relação com os preceitos da Radiologia, com a finalidade de conseguir likes ou interações em suas postagens, refletindo a atual cultura imagética e exibicionista em mídias sociais.

A pesquisa não pretende esgotar o assunto, mas abrir considerações precursoras para questionamentos e debates sobre o tema apontado, bem como sugerir a criação de um manual que aborde a disciplina Ética em âmbito digital, por parte dos estudantes e profissionais desta área, na intenção de preservar a seriedade e a imagem dos profissionais de Técnicas Radiológicas.

\section{REFERÊNCIAS}

ANVISA. Portaria SVS/MS $n^{\circ}$ 453, de 1 de junho de 1998. Aprova o Regulamento Técnico que estabelece as diretrizes básicas de proteção radiológica em radiodiagnóstico médico e odontológico, dispõe sobre o uso dos raios- $x$ diagnósticos em todo território nacional e dá outras providências. Brasília, 1998. Disponível em: http://www.conter.gov.br/uploads/legislativo/po rtaria 453.pdf. Acesso em 10 out. 2017.

BARBOSA, V. M. Códigos de Ética para mídias sociais: a preocupação com o comportamento do público interno no ciberespaço. In: CONGRESSO BRASILEIRO DE CIÊNCIAS DA COMUNICAÇÃO INTERCOM, 34., 2011, Recife. Anais [...] Recife, 2011. Disponível em:

http://www.intercom.org.br/papers/nacionais/2 011/resumos/R6-2961-1.pdf. Acesso em 22 set. 2017.

BLOCH, S.; WHITELEY, P. Você globalizado: dez estratégias para atuar como um executivo global. São Paulo: Rai, 2011.

BRASIL. Casa Civil. Subchefia para assuntos jurídicos. Lei no 12.842, de 10 de julho de 2013. Dispõe sobre o exercício da Medicina. Brasília, 2013. Disponível em:

http://www.planalto.gov.br/ccivil 03/ ato20112014/2013/lei/l12842.htm. Acesso em 18 set. 2017.

BRASIL. Lei no 12.965, de 23 de abril de 2014. Estabelece princípios, garantias, direitos e deveres para o uso da Internet no Brasil. Brasília, 2014. Disponível em: http://www.planalto.gov.br/ccivil_03/_Ato20112014/2014/Lei/L12965.htm Acesso em 18 set. 2017. 
BRASIL. Constituição da república federativa do Brasil. Brasília, 1988.

CARLSON, N. At last - the full story of how Facebook was founded. Business Insider, New York, 5. mar. 2010. Disponível em: http://www.businessinsider.com/how-facebookwas-founded-2010-3. Acesso em: 10 out. 2017.

CASTELLS, M. Redes de indignação e esperança: movimentos sociais na era da internet. Rio de Janeiro: Zahar, 2013.

A sociedade em rede. São Paulo: Paz e Terra, 1999. v. 1.

CONTER. CONSELHO NACIONAL DE TÉCNICOS EM RADIOLOGIA. Resolução no. 15 de 12 de dezembro de 2011a. Dispõe sobre a Reformulação do Código de Ética dos Profissionais das Técnicas Radiológicas. Revoga a Resolução CONTER no. 06 de 31/05/2006 e seu anexo. Brasília, 2011a. Disponível em: http://conter.gov.br/uploads/legislativo/h. 1520 11.pdf. Acesso em 20 set. 2017.

CONTER. CONSELHO NACIONAL DE TÉCNICOS EM RADIOLOGIA. Resolução n. 10 de 11 de novembro de 2011b. Regula e Disciplina o Estágio Curricular Supervisionado na Área das Técnicas Radiológicas. Brasília, 2011b. Disponível em:

http://conter.gov.br/uploads/legislativo/h. 1020 11.pdf. Acesso em 18 set. 2017.

CONTER. CONSELHO NACIONAL DE TÉCNICOS EM RADIOLOGIA. Resolução n.o 02 de 04 de maio de 2012. Institui e normatiza atribuições, competências e funções do Profissional Tecnólogo em Radiologia. Brasília, 2012. Disponível em:

http://conter.gov.br/uploads/legislativo/h. 022 012 derrogada.pdf. Acesso em 20 set. 2017.

CONTER. CONSELHO NACIONAL DE TÉCNICOS EM RADIOLOGIA. Resolução n. 11 de $\mathbf{1 5}$ de agosto de 2016. Institui e normatiza as atribuições, competência e funções dos Técnicos e Tecnólogos em Radiologia no setor Industrial, revoga as Resoluções CONTER n.o 18/2006, 21/2006, 07/2016 e dá outras providências. Brasília, 2016. Disponível em: http://conter.gov.br/uploads/legislativo/resoluca oconter 112016.pdf. Acesso em 21 set. 2017. GIL, A. C. Métodos e técnicas de pesquisa social. 6. ed. São Paulo: Atlas SA, 2008.

HERDY, T. Após compartilhar dados sigilosos de Marisa, médica do Sírio é demitida. O Globo, Rio de Janeiro, 2 fev. 2017. Disponível em: https://oglobo.globo.com/brasil/apos-

compartilhar-dados-sigilosos-de-marisa-medicado-sirio-demitida-20864217. Acesso em 14 dez. 2017.

HORA 7. Polêmica! Enfermeiras fazem selfie ao lado de paciente debilitada para comemorar último dia de trabalho. R7, São Paulo, 8 jul. 2016. Disponível em:

https://hora7.r7.com/fotos/polemicaenfermeiras-fazem-selfie-ao-lado-de-pacientedebilitada-para-comemorar-ultimo-dia-detrabalho-10072017\#!/foto/20. Acesso em $15 \mathrm{dez}$. 2017.

JENKINS, H. Cultura da convergência: a colisão entre os velhos e novos meios de comunicação. São Paulo: Aleph, 2009.

LEVINSON, P. New new media. 2. ed. Boston: Pearson, 2009.

MARTORELL, L. B.; NASCIMENTO, W. F. ; GARRAFA, V. Redes sociais, privacidade, confidencialidade e ética: a exposição de imagens de pacientes no Facebook. Interface: Comunicação, Saúde, Educação, v. 20, n. 56, p. 13-23, jan/mar. 2016.

https://doi.org/10.1590/1807-57622014.0902

McLUHAN, M. Understanding Media: The extensions of man. New York: McGraw-Hill. 1964.

MOORE, K. A história esquecida das "radium girls", cujas mortes salvaram as vidas de milhares de trabalhadores. BuzzFeed, Brasil, 02 jun. 2017. Disponível em:

https://www.buzzfeed.com/authorkatemoore/ra dium-girls-brasil?utm_term=.bpkaLxY 4\#.faEyokYa. Acesso em 19 dez. 2017.

MOREIRA, I. Novos botões de reação no Facebook para download. \#dicasdogreb, 2016. Disponível em:

http://www.dicasdogreb.com.br/novos-botoesreacao-Facebook/. Acesso em 22 set. 2017. 
ROCHA NETO, M. ; BARRETO, L. K. S.; SOUZA, L. A. As mídias sociais digitais como ferramentas de comunicação e marketing na contemporaneidade. Quipus, v. 4, n. 2, p. 11-21, jun/nov. 2015.

NOTÍCIAS. Resoluções do CFM e Cofen proíbem exposição de pacientes nas redes sociais. IMIP (Instituto de Medicina Integral Professor Fernando Figueira), 31 jan. 2018. Disponível em: http://www1.imip.org.br/imip/noticias/resolucoe s-do-cfm-e-cofen-proibem-exposicao-depacientes-nas-redes-sociais.html. Acesso em: 07 fev. 2018.

OLIVEIRA, M. R. N. S. Formação e profissionalização dos professores do ensino técnico. Educação \& Tecnologia., Belo Horizonte, v. 11, n. 2, jul/dez. 2006.

PATEL, S. S. et al. Professional social networking in radiology: who is there and what are they doing? Academic Radiology, v. 24, n. 5, p. 574579, maio 2017.

https://doi.org/10.1016/j.acra.2016.09.026

RECUERO, R. Redes sociais na internet. Porto Alegre: Sulina, 2011.

ROMANS, L. E. Computed Tomography for technologists: a comprehensive text. Philadelphia: The Point. 2011.

SCOLARI, C. A. Ecología de los medios: entornos, evoluciones e interpretaciones. Barcelona: Gedisa Editorial, 2015.

SECOM. SECRETARIA DE COMUNICAÇÃO SOCIAL. Manual de Orientação para Atuação em Mídias Sociais: Identidade Padrão de Comunicação Digital do Poder Executivo Federal. 2. ed. [Internet], 2014. Disponível em:

http://www.secom.gov.br/pdfs-da-area-deorientacoes-gerais/internet-e-redes-

sociais/secommanualredessociaisout2012 pdf.pd f. Acesso em 17 nov. 2017.

SOUZA, E. de. Grr, Uau, Haha... Entenda significados dos botões do Facebook Reactions. 26 fev. 2016. Techtudo. Disponível em: https://www.techtudo.com.br/dicas-etutoriais/noticia/2016/02/grr-uau-haha-entendasignificados-dos-botoes-do-facebookreactions.html. Acesso em 18 out. 2019.
WANG, T. A.; CHOU, C. F.; BIH, H. D. Study of Facebook Space Pattern Based on User Behaviors. In: ACM-2017 INTERNATIONAL CONFERECEN ON DATA MINING, COMMUNICATIONS AND INFORMATION TECHNOLOGY (DMCIT 2017), 2017, Phuket. Anais [...]. Phuket, 2017. Disponível (para compra) em:

https://dl.acm.org/purchase.cfm?id=3089891

Acesso em 14 nov. 2017.

https://doi.org/10.1145/3089871.3089891

WHITLEY, A. et al. The Hip, Pelvis and Sacro-iliac Joints. In: WHITLEY, A. et al. Clark's Positioning in Radiography. 12 ed. New York: CRC Press, 2005. p. 141-62. https://doi.org/10.1201/b13640-6 